\title{
Synthesis and properties of stereo di- and tri-block polylactides of different block compositions by terminal Diels-Alder coupling of poly-L-lactide and poly-D-lactide prepolymers
}

\author{
Kazunari Masutani ${ }^{1}$, Chan Woo Lee ${ }^{2}$ and Yoshiharu Kimura ${ }^{1}$ \\ Mono-anthracene-terminated poly-L-lactide (A-PLLA) and mono-maleimide-terminated poly-D-lactide (M-PDLA) were prepared \\ by ordinary lactide polymerization with initiators containing the corresponding functional groups. The resulting A-PLLA was \\ allowed to dimerize by the reaction of its terminal hydroxyl with hexamethylene diisocyanate (HMDI) to obtain bis-anthracene- \\ terminated PLLA (A-PLLA-A). The terminal Diels-Alder coupling between A-PLLA and M-PDLA and between A-PLLA-A and \\ M-PDLA spontaneously gave stereo di- (d-sb-PLA) and tri-block (t-sb-PLA) copolymers, respectively, whose block sequences \\ could be readily controlled by changing the molecular weight of the A-PLLA and M-PDLA prepolymers. The resultant d-sb-PLA \\ and $t$-sb-PLA samples were found to have excellent thermal and thermo-mechanical properties due to the easy formation of \\ stereocomplex crystals of PLLA and PDLA. These synthetic methods, which were based on polymer coupling, can be a facile \\ route to the fabrication of stereo block polylactides possessing excellent properties.
}

Polymer Journal (2013) 45, 427-435; doi:10.1038/pj.2012.161; published online 12 September 2012

Keywords: poly-L-lactide; poly-D-lactide; Diels-Alder coupling; stereo block copolymer; stereocomplex; thermal properties

\section{INTRODUCTION}

Much recent attention has been paid to both biobased polymers that can be synthesized from naturally occurring substances and platform chemicals derived from biomass by combining the biological and chemical conversion processes. Until now, several aliphatic polyesters, such as poly(lactide)s (PLA), poly(butylene succinate) (PBS), and poly(3-hydroxyalkanoate)s (PHA), have been accepted by industries as the first manufacturing products. ${ }^{1}$ Bio-originated polyamides, polycarbonates, and acrylic polymers are now under development as next generation polymers. Among these biobased polymers, only PLAs are now manufactured on a large scale and used as plastic materials for general purposes. Two enantiomeric isomers, poly-Llactide (PLLA) and poly-D-lactide (PDLA), are present in PLAs depending on the chirality of the lactic acid component, and PLLA, consisting of naturally abundant L-lactic acid, is generally utilized because of its balanced properties and cost. $^{2-4}$ In practical applications, however, the thermal and mechanical properties of PLLA are significantly poorer than those of the conventional oilbased polymers, which limits its utility. ${ }^{5}$ Therefore, much effort has been made to improve the resistance of PLLA to heat. However, it is known that the combination of enantiomeric PLLA and PDLA generates stereocomplex (sc) crystals that exhibit a melting temperature $\left(\mathrm{T}_{\mathrm{m}}\right)$ of $230{ }^{\circ} \mathrm{C}$, i.e., $50^{\circ} \mathrm{C}$ higher than that of PLLA. ${ }^{6-10}$ The stereocomplex-type PLA (sc-PLA) can achieve high performance materials with a degree of heat resistance that has never been accomplished with PLLA alone. However, the simple mixing of PLLA and PDLA polymers with high molecular weight likely results in the formation of both homo-chiral (hc) and sc crystals to retard the heat resistibility of the processed materials. ${ }^{7,8}$ Therefore, we have pursued the development of stereoblock-type polylactides (sb-PLA) consisting of PLLA and PDLA sequences because even with PLLArich compositions, sb-PLAs can easily form sc crystals with little hc crystallization and exhibit excellent properties. ${ }^{11-19}$ This improved sc crystallization can be attributed to molecular mixing within the enantiomeric blocks. We have recently disclosed a novel method for the synthesis of stereo di-block PLAs (d-sb-PLA) by the terminal Diels-Alder coupling of PLLA and PDLA prepolymers with anthracene and maleimide terminal moieties. ${ }^{19}$ In this approach, for example, mono-anthranyl PLLA (A-PLLA) and mono-maleimid-N-yl PDLA (M-PDLA) prepolymers are first prepared by the ordinary ring-opening polymerization (ROP) of $\mathrm{L}^{-}$and $\mathrm{D}$-lactides, respectively. These mono-functional prepolymers are mixed and then undergo the Diels-Alder coupling to finally obtain a d-sb-PLA with a high molecular weight (Scheme 1). This method is characterized by

${ }^{1}$ Department of Biobased Materials Science, Kyoto Institute of Technology, Matsugasaki, Sakyo-ku, Kyoto, Japan and ${ }^{2}$ Department of Innovative Industrial and Technology, Hoseo University, Baebang-Myun, Asan, Chungnam, Korea

Correspondence: Professor Y Kimura, Department of Biobased Materials Science, Kyoto Institute of Technology, Matsugasaki, Sakyo-ku, Kyoto 606-8585, Japan.

E-mail: ykimura@kit.ac.jp

Received 19 December 2011; revised 1 June 2012; accepted 6 July 2012; published online 12 September 2012 
a<smiles>CC1OC(=O)C(C)OC1=O</smiles>

L-lactide

b<smiles>C[C@@H]1OC(=O)[C@H](C)OC1=O</smiles>

D-lactide

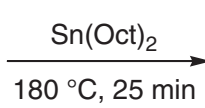<smiles>CC(O)C(=O)OCc1ccc2cc3ccccc3cc2c1</smiles>

A-PLLA<smiles>CC(=O)OCCN1C(=O)C=CC1=O</smiles>

Scheme 1 The synthesis of A-PLLA and M-PDLA and the following Diels-Alder coupling to obtain the d-sb-PLAs.

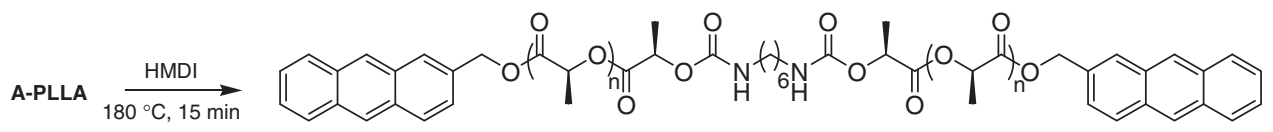

A-PLLA-A

Scheme 2 The synthesis of A-PLLA-A by the dimerization of A-PLLA.

well-controlled block lengths and compositions that can be determined by the molecular weights of the prepolymers as well as by the excellent stereo-complexibility of the resultant d-sb-PLAs. In this study, we prepare various d-sb-PLAs with different PLLA and PDLA block lengths and compositions by utilizing this terminal coupling method. We also synthesize stereo tri-block PLAs (t-sb-PLA) by expanding this method to other prepolymer combinations in which M-PDLAs are reacted with bis-anthranyl PLLAs (A-PLLA-A) prepared by the reaction of the hydroxyl terminal of A-PLLAs (the alternative terminal group) with 1,6-hexamethylene diisocyanate (HMDI) for dimerization (Scheme 2). Then, the Diels-Alder reactions of the di-functional A-PLLA-A and the mono-functional M-PDLA prepolymers are conducted to obtain t-sb-PLAs (PDLA-PLLA-PDLA) with different block sequences and lengths (Scheme 3). With these $\mathrm{d}$ - and t-sb-PLA samples, we clarify the relationship between the thermal properties and the block structures.

\section{MATERIALS AND METHODS}

\section{Materials}

The L- and D-lactides were supplied by Musashino Chemical Research Laboratory, Ltd. (Tokyo, Japan). Their optical purity was over $99.9 \%$ ee. 2-(Hydroxymethyl)anthracene (AN, 98\%) and HMDI were supplied by Tokyo Chemical Industry Co., Ltd. (Tokyo, Japan). N-(2-Hydroxyethyl)maleimide $(\mathrm{MA}, 99 \%)$ and tin octoate $\left(\mathrm{Sn}(\mathrm{Oct})_{2}, 95 \%\right)$ were purchased from Strem Chemicals (Newburyport, MA) and Sigma-Aldrich (St Louis, MO), respectively, via Sasaki Chemical Co., Ltd. (Kyoto, Japan). The $\mathrm{Sn}(\mathrm{Oct})_{2}$ was purified by distillation before use and dissolved in distilled toluene at a concentration of $0.20 \mathrm{~g} / \mathrm{ml}$ under a nitrogen atmosphere. Dichloromethane $\left(\mathrm{CH}_{2} \mathrm{Cl}_{2}, 99.5 \%\right)$ and 1,1,1,3,3,3-hexafluoro-2-propanol (HFIP, 98\%) were purchased from Kanto Chemical Co., Ltd. (Tokyo, Japan) and Central Glass Co., Ltd. (Hofu, Yamaguchi, Japan), respectively. These reagents and solvents were used without purification, unless specifically noted.

\section{Measurements}

The number- $\left(\mathrm{M}_{\mathrm{n}}(\mathrm{gpc})\right)$ and weight-average $\left(\mathrm{M}_{\mathrm{w}}(\mathrm{gpc})\right)$ molecular weights were determined by gel permeation chromatography (GPC) recorded on a system comprised of a Shimadzu (Kyoto) LC-20AD HPLC pump and a Shimadzu RID-10 A differential refractive index detector. Two Tosoh (Tokyo, Japan) TSK gel Super HZM-N columns $(3.0 \mu \mathrm{m}$ in bead size, molecular weight exclusion range of $700000-500 \mathrm{Da}$ ) with a Tosoh TSK Super HZ-L guard column $(4.6 \mathrm{~mm} \mathrm{ID} \times 3.5 \mathrm{~cm})$ were installed in the system, and chloroform was used as the eluent. The measurement was carried out at $30^{\circ} \mathrm{C}$ at a flow rate of $0.25 \mathrm{ml} \mathrm{min}^{-1}$. Polystyrene (PS) standards were used to calibrate the molecular weights, which ranged from 1090000 to $500 \mathrm{Da}$. The ${ }^{1} \mathrm{H}$ NMR $(600 \mathrm{MHz})$ spectra were recorded on a Bruker (Karlsruhe, Germany) AV600 spectrometer for samples dissolved in deuterated chloroform using $0.03 \mathrm{vol}-\%$ tetramethylsilane (TMS) as the internal standard. Differential scanning calorimetry (DSC) was conducted on a Shimadzu DSC-50 thermal analyzer under a nitrogen flow of $20 \mathrm{ml} \mathrm{min}^{-1}$ and at a heating rate of $10^{\circ} \mathrm{C} \mathrm{min}-1$. A sample of approximately $3.0 \mathrm{mg}$ was heated to $240^{\circ} \mathrm{C}$ in the first scan, quenched in liquid nitrogen, and heated again from $30^{\circ} \mathrm{C}$ to $250^{\circ} \mathrm{C}$ in the second heating scan. Wide-angle X-ray scattering (WAXS) patterns were recorded on a Rigaku 2100 FSL X-ray diffraction system with a Rigaku RINT $2000 \mathrm{X}$-ray generator operated at $40 \mathrm{kV}$ and $50 \mathrm{~mA}$, using nickel-filtered $\mathrm{Cu}-\mathrm{K} \alpha$ radiation $(\lambda=0.1542 \mathrm{~nm})$ in a $2 \theta$ angle range from $5^{\circ}$ to $40^{\circ}$ at a scan rate of $2^{\circ} \mathrm{min}^{-1}$. Dynamic mechanical analysis (DMA) was measured on a RheogelE4000 (UBM Co., Ltd., Japan) working in the tension mode at a constant frequency of $10 \mathrm{~Hz}$. The measurements were carried out in a temperature range from 30 to $240{ }^{\circ} \mathrm{C}$ at a heating rate of $3{ }^{\circ} \mathrm{C} \mathrm{min}{ }^{-1}$. 
<smiles>C[C@H](O)C(=O)OCCN1C(=O)C=CC1=O</smiles>

M-PDLA

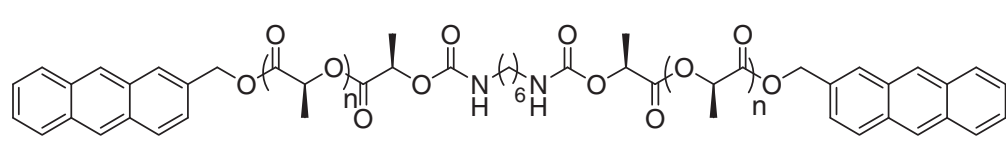

A-PLLA-A

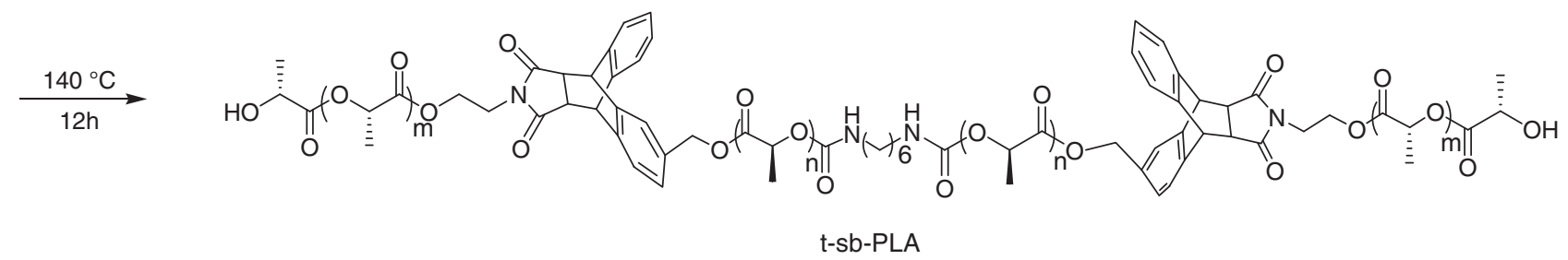

Scheme 3 The Diels-Alder couplings of M-PDLA and A-PLLA-A to obtain the tri-sb-PLAs.

\section{Syntheses of A-PLLA and M-PDLA}

The procedures used here have been reported previously. To synthesize the A-PLLA, both the L-lactide $(3.0 \mathrm{~g}, 20.8 \mathrm{mmol})$ and AN $(41.7 \mathrm{mg}, 0.20 \mathrm{mmol})$ were charged in a 50-ml, two-necked flask equipped with a mechanical stirrer. The flask was evacuated to $10 \mathrm{~Pa}$ at room temperature for $1 \mathrm{~h}$ and then purged with nitrogen. The evacuation/nitrogen purge was repeated six times to thoroughly dry the reactants. Subsequently, a portion of the catalyst solution (including $0.083 \mathrm{mmol}$ of $\mathrm{Sn}(\mathrm{Oct})_{2}$, i.e., $0.4 \mathrm{~mol} \%$ of L-lactide) was added to it with a syringe. The flask was desiccated at high vacuum for $1 \mathrm{~h}$ at room temperature to remove the toluene and then was filled with nitrogen. Next, the flask was heated at $180^{\circ} \mathrm{C}$ for $25 \mathrm{~min}$ while stirring for polymerization. The polymeric product was dissolved in $\mathrm{CH}_{2} \mathrm{Cl}_{2}$ and poured into excess methanol. The precipitate was filtered, washed with methanol several times, and dried in vacuum to obtain the A-PLLA with an $\mathrm{M}_{\mathrm{n}}$ of $15 \mathrm{kDa}$.

To synthesize the M-PDLA, both D-lactide $(3.0 \mathrm{~g}, 20.8 \mathrm{mmol})$ and MA ( $28.2 \mathrm{mg}, 0.2 \mathrm{mmol}$ ) were charged in a $50-\mathrm{ml}$, two-necked flask equipped with a mechanical stirrer and thoroughly dried under vacuum. Subsequently, a portion of the catalyst solution (including $0.083 \mathrm{mmol}$ of $\mathrm{Sn}(\mathrm{Oct})_{2}$, i.e., $0.4 \mathrm{~mol} \%$ of D-lactide) was added to the flask. Then, the polymerization and product isolation were conducted as described above to yield the M-PDLA with an $\mathrm{M}_{\mathrm{n}}$ of $15 \mathrm{kDa}$.

Several A-PLLA and M-PDLA samples were synthesized with different molecular weights. In this work, the prepolymers are named A-PLLA(x) and M-PDLA(y), respectively, by putting their $\mathrm{M}_{\mathrm{n}}$ numbers, in $\mathrm{kDa}$, in the parentheses.

A-PLLA(15): ${ }^{1} \mathrm{H}$ NMR $\left(600 \mathrm{MHz}\right.$, in $\left.\mathrm{CDCl}_{3}\right): \delta 1.56-1.6\left(\mathrm{~d}, \mathrm{CH}_{3}\right.$ of the lactate unit), 4.3-4.4 (q, $\mathrm{CH}-\mathrm{OH}$ of the terminal lactate), 5.1-5.2 (q, $\mathrm{CH}$ of the lactate unit), 5.38 ( $\mathrm{AB} \mathrm{q}, \mathrm{CH}_{2}$ - of the $\mathrm{AN}$ unit), and $7.41(\mathrm{dd}), 7.5-7.6(\mathrm{~m})$, 7.97 (s), 8.03 (d), 8.45 (s) for the aromatic protons of the AN unit. The $M_{n}$ $(\mathrm{nmr})$ was determined by the integral ratios of the signals at $\delta 4.3-4.4$ and $\delta$ 5.1-5.2 p.p.m.

M-PDLA(15): ${ }^{1} \mathrm{H}$ NMR $\left(600 \mathrm{MHz}\right.$, in $\left.\mathrm{CDCl}_{3}\right): \delta 1.56-1.6$ (d, $\mathrm{CH}_{3}$ of the lactate unit), 4.3-4.4 (q, $\mathrm{CH}-\mathrm{OH}$ of the terminal lactate), 5.1-5.2 (q, $\mathrm{CH}$ of the lactate unit), and 3.7-3.9 (m, N-CH $-\mathrm{C}$ of the MA unit), 4.2-4.4 (m, C- $\mathrm{CH}_{2}-\mathrm{O}$ of the MA unit), and 6.75 (s, $-\mathrm{CH}=\mathrm{CH}$ - of the MA unit). The $\mathrm{M}_{\mathrm{n}}$ (nmr) was determined by the integral ratios of the signals at $\delta$ 5.1-5.2 and $\delta$ 4.3-4.4 p.p.m. Because the latter signal was duplicated with the $\mathrm{C}-\mathrm{CH}_{2}-\mathrm{O}$ signal of the MA unit, its integral ratio was evaluated in reference to that of the $\mathrm{N}-\mathrm{CH}_{2}-\mathrm{C}$ signal of the MA unit.

\section{Synthesis of A-PLLA-A}

For example, the A-PLLA(7.5) was first prepared by the ROP of L-lactide $(3.0 \mathrm{~g}, 20.8 \mathrm{mmol})$ by using $\mathrm{AN}(83.3 \mathrm{mg}, 0.40 \mathrm{mmol})$ and $\mathrm{Sn}(\mathrm{Oct})_{2}(0.4 \mathrm{~mol} \%$ of L-LA) as the initiator and catalyst, respectively, as described in the above synthesis of A-PLLA. In the final step of this polymerization, exactly half an equivalent molar amount of HMDI $(34 \mathrm{mg}, 0.20 \mathrm{mmol}$ ) relative to AN was added to the system and reacted with the polymerization product for $15 \mathrm{~min}$ while stirring under identical conditions. The obtained reaction product was finally dissolved in $\mathrm{CH}_{2} \mathrm{Cl}_{2}$ and then re-precipitated with excess methanol. The precipitates were filtered, washed with methanol several times, and dried under vacuum at $80^{\circ} \mathrm{C}$ for $6 \mathrm{~h}$.

Several A-PLLA-A samples with different molecular weights were synthesized from the corresponding A-PLLA prepolymers. These A-PLLA-A prepolymers are also named A-PLLA-A $(2 x)$, in which $2 x$ denotes the $M_{n}$ values, which are nearly twice that $(\mathrm{x})$ of the A-PLLA prepolymers.

A-PLLA-A(15): ${ }^{1} \mathrm{H}$ NMR $\left(600 \mathrm{MHz}\right.$, in $\mathrm{CDCl}_{3}$, Figure 1): $\delta 1.3-1.4(\mathrm{~s}$, $\mathrm{C}-\mathrm{CH}_{2}-\mathrm{C}$ of the HMDI unit), $1.56-1.6$ (d, $\mathrm{CH}_{3}$ of the lactate unit), 3.1-3.2 (q, $\mathrm{N}-\mathrm{CH}_{2}-\mathrm{C}$ of the HMDI unit), 4.9-5.0 (q, C-CH-OC(O)NH- of the linking lactate), 5.1-5.2 (q, $\mathrm{CH}$ of the lactate unit), 5.38 ( $\mathrm{AB} \mathrm{q}, \mathrm{CH}_{2}$ - of the $\mathrm{AN}$ unit), and $7.41(\mathrm{dd}), 7.5-7.6(\mathrm{~m}), 7.97(\mathrm{~s}), 8.03(\mathrm{~d}), 8.45(\mathrm{~s})$ for the aromatic protons of the AN unit.

\section{Synthesis of d-sb-PLA by Diels-Alder Coupling of A-PLLA and M-PDLA}

The reaction process has been reported previously. ${ }^{19}$ In summary, predetermined amounts of A-PLLA (15) (1.0 g) and M-PDLA(15) (1.0 g) were dissolved in a mixture of $\mathrm{CH}_{2} \mathrm{Cl}_{2}$ and $\operatorname{HFIP}\left(5 \mathrm{ml}, \mathrm{CH}_{2} \mathrm{Cl}_{2} / \mathrm{HFIP}=4 / 1\right.$ $\mathrm{v} / \mathrm{v} \%)$ and reprecipitated into excess methanol. The precipitated polymer mixture was dried under vacuum at room temperature for $3 \mathrm{~h}$. A portion of the polymer mixture was charged in a glass reactor and heated at $140{ }^{\circ} \mathrm{C}$ under a nitrogen atmosphere for $12 \mathrm{~h}$. While heating, the polymer mixture softened in the early stage and solidified quickly after the Diels-Alder reaction process. The resulting polymer was reprecipitated by using a solvent system of $\mathrm{CH}_{2} \mathrm{Cl}_{2}$ / HFIP mixture (solvent) and methanol (precipitant) and dried under vacuum at $80{ }^{\circ} \mathrm{C}$ for $8 \mathrm{~h}$. The polymer samples resulting from the combinations of A-PLLA (x) and M-PDLA(y) are named d-sb-PLA (x-y).

d-sb-PLA (15-15): ${ }^{1} \mathrm{H}$ NMR (600 MHz, $\mathrm{CDCl}_{3}$ ): 1.56-1.6 (d, $\mathrm{CH}_{3}$ for PLA), 4.9-5.0 (s, C-CH-O at the terminal of PLA), 5.1-5.2 (q, CH for PLA), $4.78(\mathrm{~d})$, and 7.1-7.4 (m) (for the anthracene unit), 3.3-3.4 (m), and 3.6-3.8 (m) (for the maleimide unit), 3.1-3.3 (m), and 3.4-3.6 (m) (for the connections of the Diels-Alder adduct).

\section{Synthesis of t-sb-PLA by Diels-Alder Coupling of A-PLLA-A and M-PDLA}

A typical example follows. Predetermined amounts of A-PLLA-A(15) (1.0 g) and M-PDLA(7.5) (1.0 g) were dissolved in a mixture of $\mathrm{CH}_{2} \mathrm{Cl}_{2}$ and HFIP $\left(5 \mathrm{ml}, \mathrm{CH}_{2} \mathrm{Cl}_{2} / \mathrm{HFIP}=4 / 1 \mathrm{v} / \mathrm{v} \%\right)$ at room temperature. The solution was then poured into excess methanol to precipitate the polymer mixture of A-PLLA$\mathrm{A}(15)$ and M-PDLA(7.5). The precipitates were dried under vacuum at $80^{\circ} \mathrm{C}$ for $8 \mathrm{~h}$ and then pulverized. The subsequent Diels-Alder reaction and product isolation were conducted as described in the above synthesis of d-sb-PLA. The 


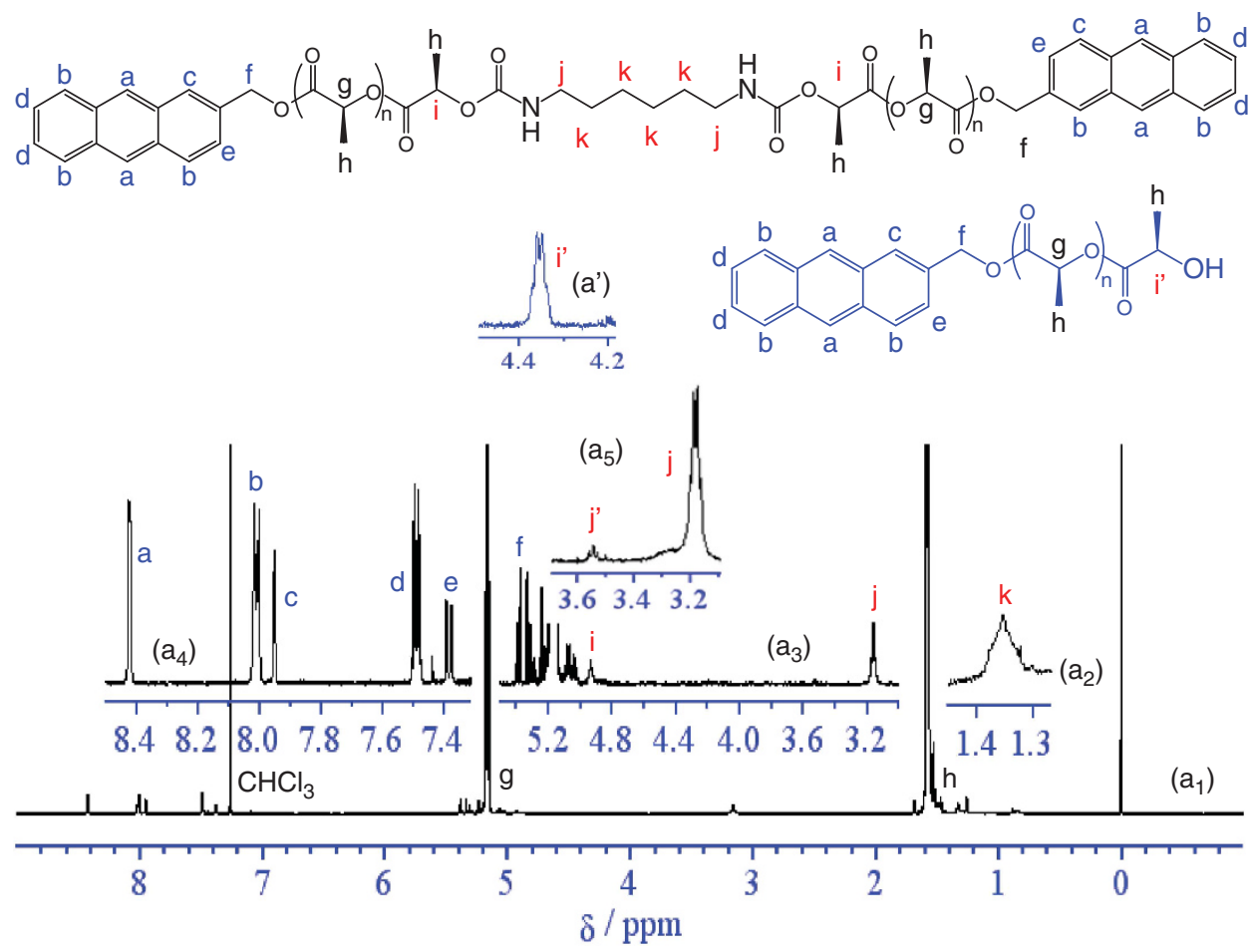

Figure 1 The ${ }^{1} \mathrm{H}$ NMR spectra of A-PLLA-A(15): $\left(a_{1}\right)$ a full spectrum, $\left(a_{2}-a_{5}\right)$ the expanded spectra for the weak signals, and $\left(a^{\prime}\right)$ an expanded spectrum of the A-PLLA(7.5) for comparison.

resulting polymer samples were prepared from the combinations of A-PLLA$\mathrm{A}(2 \mathrm{x})$ and M-PDLA(y) and were named t-sb-PLA(y-2x-y).

t-sb-PLA(7.5-15-7.5): ${ }^{1} \mathrm{H}$ NMR (600 MHz, $\mathrm{CDCl}_{3}$, Figure 2): 1.56-1.6 (d, $\mathrm{CH}_{3}$ for PLA), 4.9-5.0 (s, C-CH-O at the terminal of PLA), 5.1-5.2 (q, CH for PLA), 4.78 (d), and 7.1-7.4 (m) (for the anthracene unit), 3.3-3.4 (m), and 3.6-3.8 (m) (for the maleimide unit), and 1.3-1.4 (s, C- $\mathrm{CH}_{2}-\mathrm{C}$ for HMDI unit), 3.1-3.2 (q, N-CH $-\mathrm{CH}_{2}-\mathrm{C}$ for HMDI unit), 3.1-3.3 (m), and 3.4-3.6 (m) (for the connections of the Diels-Alder adduct).

\section{Preparation of Hot-pressed Films}

Each polymer sample was placed between two aluminum plates with a spacer size of $40 \times 40 \times 0.1 \mathrm{~mm}^{3}$ and subjected to hot-pressing using an Mini Test Press Model MP-2FH (TOYOSEKI Co., Ltd., Japan) apparatus. The sample was melted at $240^{\circ} \mathrm{C}$, pressed at a pressure of $5 \mathrm{MPa}$ for $3 \mathrm{~min}$, and quenched in ice-water to obtain an amorphous film. The sample was then annealed at $140{ }^{\circ} \mathrm{C}$ for $3 \mathrm{~h}$.

\section{RESULTS AND DISCUSSION}

Synthesis of d-sb-PLAs having different PLLA/PDLA block ratios As reported previously, ${ }^{19}$ the mono-anthracene-terminated A-PLLA(x) and mono-maleimide-terminated M-PDLA(y) were prepared by the ordinary tin-catalyzed ROP of L- and D-lactides in the presence of AN and MA as the initiators, respectively (Schemes $1 \mathrm{a}$ and $1 \mathrm{~b}$ ). Table 1 summarizes the results of the preparations of A-PLLA(x) and M-PDLA(y) with different chain lengths. The monomer conversion was very high for each synthesis run, and the $M_{n}(n m r)$ values of the A-PLLA(x) and M-PDLA(y) prepolymers nearly corresponded to the $\mathrm{M}_{\mathrm{n}}(\mathrm{th})$ values estimated from the monomer-to-initiator ratios in the feed and monomer conversions. In comparison to the $M_{n}(n m r)$ values, the significantly larger $\mathrm{M}_{\mathrm{n}}(\mathrm{gpc})$ values may be attributed to the fact that the PLA polymers with molecular weights of the present range $\left(10^{3}-10^{4} \mathrm{kDa}\right)$ likely show larger hydrodynamic

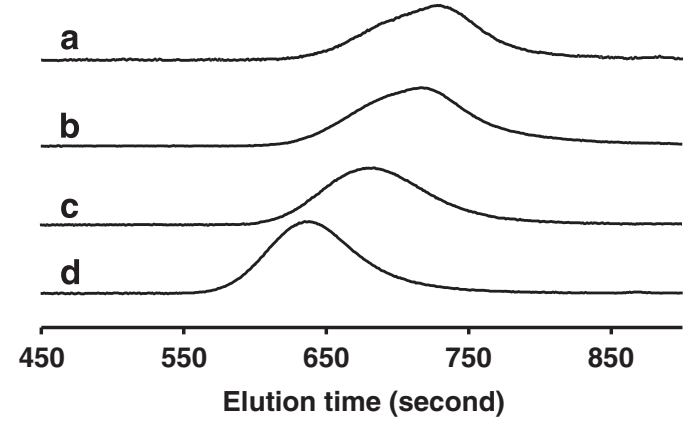

Figure 2 The GPC curves of (a) A-PLLA(7.5), (b) M-PDLA(7.5), (c) A-PLLA$A(15)$, and (d) t-sb-PLA(7.5-15-7.5).

volumes than the standard polymers in chloroform. However, the increasing tendencies of $\mathrm{M}_{\mathrm{n}}(\mathrm{nmr})$ and $\mathrm{M}_{\mathrm{n}}(\mathrm{gpc})$ were consistent with each other, supporting the correlation of the molecular weights. These data, together with the structural data shown in the Experimental section, support the formations of A-PLLA(x) and M-PDLA(y). Here, six samples were prepared for each series of A-PLLA(x) and M-PDLA(y).

By combining the A-PLLA(x) and M-PDLA(y) samples, for which the $\mathrm{M}_{\mathrm{n}}$ of the former ( $\mathrm{x}$ ) was larger than that of the latter (y), the Diels-Alder coupling reactions were conducted at $140{ }^{\circ} \mathrm{C}$ (Scheme 3) to synthesize six d-sb-PLA(x-y) samples in the form of PLLA-b-PDLA whose PLLA block was equal to or longer than the PDLA block $(x \geqslant y)$ at different block ratios (Scheme 1c). The structural characterization of the resultant d-sb-PLAs is described in the Experimental section. Table 2 summarizes the results of the coupling 
Table 1 The Synthesis of A-PLLA(x) and M-PDLA(y)

\begin{tabular}{|c|c|c|c|c|c|c|c|}
\hline Prepolymer & {$[M]_{O} /[I]_{O}$} & Conversion (\%) & $M n(t h)\left(10^{-3}\right)$ & $M n^{\mathrm{a}}(n m r)\left(10^{-3}\right)$ & $M n^{\mathrm{b}}(g p c)\left(10^{-3}\right)$ & $M w^{\mathrm{b}}(g p c)\left(10^{-3}\right)$ & $M w / M n^{b}$ \\
\hline A-PLLA (15) & 103.8 & 97.3 & 14.9 & 15.1 & 22.1 & 28.7 & 1.3 \\
\hline A-PLLA (21) & 146.1 & 98.4 & 21.0 & 21.3 & 34.1 & 47.7 & 1.4 \\
\hline A-PLLA (24) & 167.6 & 97.8 & 24.1 & 25.2 & 42.7 & 59.8 & 1.4 \\
\hline A-PLLA (50) & 347.5 & 95.2 & 50.0 & 50.2 & 71.5 & 107.2 & 1.5 \\
\hline A-PLLA (70) & 486.9 & 95.2 & 70.1 & 71.9 & 117.0 & 187.2 & 1.6 \\
\hline A-PLLA (80) & 544.5 & 95.6 & 78.4 & 77.8 & 120.0 & 180.0 & 1.5 \\
\hline M-PDLA (6) & 41.8 & 96.7 & 6.0 & 6.6 & 11.0 & 15.4 & 1.4 \\
\hline M-PDLA (9) & 62.5 & 97.6 & 9.0 & 8.6 & 15.4 & 21.6 & 1.4 \\
\hline M-PDLA (15) & 104.5 & 95.5 & 15.0 & 16.0 & 23.0 & 34.5 & 1.5 \\
\hline M-PDLA (20) & 138.9 & 96.1 & 20.2 & 21.2 & 34.1 & 47.7 & 1.4 \\
\hline M-PDLA (30) & 208.4 & 96.1 & 30.0 & 26.2 & 51.3 & 71.8 & 1.4 \\
\hline M-PDLA (50) & 347.7 & 95.8 & 50.1 & 52.4 & 73.2 & 110.0 & 1.5 \\
\hline
\end{tabular}

Determined by ${ }^{1} \mathrm{H}$ NMR.

betermined by GPC relative to polystyrene standards with $\mathrm{CHCl}_{3}$ as the eluent.

Table 2 The results of Diels-Alder Reaction of A-PLLA(x) and M-PDLA(y) to obtain d-sb-PLA(x-y)

\begin{tabular}{|c|c|c|c|c|c|c|c|c|}
\hline$d-s b-P L A x-y$ & Combination & PDLA (\%) & $M n(t h)\left(10^{-3}\right)$ & $M n^{a}(g p c)\left(10^{-3}\right)$ & $M w^{\mathrm{a}}(g p c)\left(10^{-3}\right)$ & $M w / M n^{\mathrm{a}}$ & $T_{m}^{\mathrm{b}}\left({ }^{\circ} \mathrm{C}\right)$ & $X_{c}^{c}(\%)$ \\
\hline $15-15$ & A-PLLA (15)/ M-PDLA (15) & 50 & 30.1 & 46.3 & 81.8 & 1.8 & 235.5 & 34.9 \\
\hline $21-9$ & A-PLLA (21)/ M-PDLA (9) & 30 & 30.0 & 43.2 & 84.2 & 1.9 & 229.6 & 30.4 \\
\hline $24-6$ & A-PLLA (24)/ M-PDLA (6) & 20 & 29.9 & 43.4 & 95.2 & 2.2 & 219.3 & 24.7 \\
\hline $50-50$ & A-PLLA (50)/ M-PDLA (50) & 50 & 98.6 & 91.0 & 220.0 & 2.4 & 215.4 & 33.9 \\
\hline $70-30$ & A-PLLA (70)/ M-PDLA (30) & 30 & 100.1 & 105.2 & 188.2 & 1.8 & 205.2 & 24.2 \\
\hline $80-20$ & A-PLLA (80)/ M-PDLA (20) & 20 & 100.0 & 113.5 & 188.7 & 1.7 & 206.2 & 17.6 \\
\hline
\end{tabular}

aDetermined by GPC relative to polystyrene standards with $\mathrm{CHCl}_{3}$ as the eluent.

DDetermined by DSC (the 2nd scan).

${ }^{c}$ Calculated on the basis of the specific heat of fusions of sc crystals (142 J/g).

reactions. Here, the total $\mathrm{M}_{\mathrm{n}}(\mathrm{th})$ values of the $\mathrm{d}$-sb-PLAs were 30 and $100 \mathrm{kDa}$ in the series with $\mathrm{x}-\mathrm{y}$ indices of $24-6,21-9$, and $15-15$ and those with $x-y$ of $80-20,70-30$ and 50-50, respectively. The former series exhibited somewhat larger $M_{n}(\mathrm{gpc})$ values than the $M_{n}(t h)$ values estimated from the total $\mathrm{M}_{\mathrm{n}}(\mathrm{th})$ values of the two prepolymers, whereas the latter series, with higher molecular weights, had $\mathrm{M}_{\mathrm{n}}(\mathrm{gpc})$ values almost equal to the $\mathrm{M}_{\mathrm{n}}(\mathrm{th})$ values, supporting the almost quantitative Diels-Alder coupling between the anthracene and maleimide terminals. ${ }^{19}$

\section{Synthesis of A-PLLA-A}

Because each of the anthracene-terminated A-PLLA samples possesses a hydroxyl group in the opposite polymer tail, it can be used for the post-polymerization reaction with HMDI. Hence, as soon as the first ROP of L-lactide was concluded, we added HMDI (a half molar amount of the initiator AN) to the as-formed A-PLLA without isolation for its dimerization (one-pot reaction). Because the $\mathrm{Sn}(\mathrm{Oct})_{2}$ used for the ROP was able to sufficiently catalyze the urethane formation between the isocyanate and hydroxyl groups, the dimeric product A-PLLA-A $(2 \mathrm{x})$ was obtained in a high conversion rate in a short reaction time of $15 \mathrm{~min}$. Figure 1 shows a typical ${ }^{1} \mathrm{H}-\mathrm{NMR}$ spectrum of the as-prepared A-PLLA-A(15) sample, in which several characteristic signals are enlarged in spectra $\mathrm{a}_{3}-\mathrm{a}_{5}$ and compared with the signal $\left(\mathrm{a}^{\prime}\right)$ in the spectrum of the A-PLLA(7.5) prepolymer. The signal assignments are designated by the alphabetical symbols and summarized in the Experimental section. In summary, A-PLLA(7.5) exhibits a hydroxymethine signal due to the terminal lactate unit at $\delta 4.3-4.4$ p.p.m. (signal $i^{\prime}$ in the expanded spectrum $\mathrm{a}^{\prime}$ for
A-PLLA(7.5)). This signal is completely absent in A-PLLA-A(15) and is replaced by the carbamoyloxymethine signal shown at $\delta 4.9-5.0$ p.p.m. (signal $i$ in spectrum $a_{3}$ ), which can be attributed to the linking of the lactate unit with the urethane group. Additionally, A-PLLA$\mathrm{A}(15)$ exhibits HMDI-originated alkylene-methylene signals at $\delta 1.3-$ 1.4 p.p.m. (signal $k$ in spectrum $\mathrm{a}_{2}$ ) and $\mathrm{N}$-methylene signals at $\delta 3.1-$ 3.2 p.p.m. (signal $j$ in spectrum $a_{3}$ ), whereas the $\mathrm{N}$-methylene signal of HMDI are shown at $\delta 3.5-3.6$ p.p.m. as a very weak signal (signal $j$ ' in the expanded spectrum $a_{5}$ ), which nearly disappeared following purification. The conversion of this coupling reaction was determined from the integral ratios of the $\mathrm{N}$-methylene signals, which were identified to be as high as $97 \%$. However, the signals from the anthracene moieties (expanded spectrum $\mathrm{a}_{4}$ ) were unchanged both before and following the coupling. The spectroscopic data strongly support the dimeric structures of A-PLLA-A(15), in which two A-PLLA(7.5) chains are connected through two urethane linkages. The $\mathrm{M}_{\mathrm{n}}(\mathrm{nmr})$ values of the coupling products were estimated from the integral ratios of the methine signals of the linking units $\mathrm{C}-\mathrm{CH}$ $\mathrm{OC}(\mathrm{O}) \mathrm{NH}-(\delta$ 4.9-5.0 p.p.m.) and the main chain units $\mathrm{C}-\mathrm{CH}-$ $\mathrm{OC}(\mathrm{O})(\delta 5.1-5.2$ p.p.m.) by considering the dimeric structure.

Table 3 summarizes the examined isocyanate coupling reactions. It should be noted that the data for A-PLLA(x) are recorded for the intermediate prepolymers isolated after the ROP, which was separately performed for characterization. In the coupling reaction, the conversion exceeded $96 \%$, as described above. The non-quantitative conversion may be due to the evaporation of a small amount of HMDI while in the reaction vessel. Figure 2 compares the typical GPC curves of (a) A-PLLA(7.5) and (c) its coupling product A-PLLA-A(15). It is 
Table 3 The synthesis of A-PLLA-A(2x) by dimerization of A-PLLA(x)

\begin{tabular}{|c|c|c|c|c|c|c|c|c|c|}
\hline Prepolymer & {$[M]_{0} /[I]_{O}$} & Conversion (\%) & Coupling products & HMDI conversion (\%) & $M n(t h)\left(10^{-3}\right)$ & $M n^{\mathrm{a}}(n m r)\left(10^{-3}\right)$ & $M n^{\mathrm{b}}(g p c)\left(10^{-3}\right)$ & $M w^{b}(g p c)\left(10^{-3}\right)$ & $M w / M n^{b}$ \\
\hline \multirow[t]{2}{*}{ A-PLLA (7.5) } & 52.1 & 95.6 & & & 7.5 & 7.6 & 13.6 & 25.1 & 1.9 \\
\hline & & & A-PLLA-A (15) & 97.5 & 14.6 & & 23.4 & 41.6 & 1.8 \\
\hline \multirow[t]{2}{*}{ A-PLLA (10.5) } & 72.9 & 95.1 & & & 10.5 & 10.8 & 16.5 & 27.2 & 1.7 \\
\hline & & & A-PLLA-A (21) & 98.3 & 20.6 & & 35.0 & 63.0 & 1.8 \\
\hline \multirow[t]{2}{*}{ A-PLLA (12) } & 83.2 & 95.2 & & & 12.0 & 12.7 & 19.5 & 29.4 & 1.5 \\
\hline & & & A-PLLA-A (24) & 97.5 & 23.4 & & 40.0 & 72.0 & 1.8 \\
\hline \multirow{2}{*}{ A-PLLA (25) } & 173.0 & 94.5 & & & 24.9 & 22.0 & 37.4 & 68.4 & 1.8 \\
\hline & & & A-PLLA-A (50) & 97.0 & 48.3 & & 62.3 & 116.0 & 1.9 \\
\hline \multirow[t]{2}{*}{ A-PLLA (35) } & 243.0 & 94.0 & & & 35.0 & 31.1 & 60.9 & 108.0 & 1.8 \\
\hline & & & A-PLLA-A (70) & 97.0 & 67.9 & & 113.0 & 200.0 & 1.8 \\
\hline \multirow[t]{2}{*}{ A-PLLA (40) } & 278.0 & 94.9 & & & 40.0 & 37.0 & 68.2 & 123.0 & 1.8 \\
\hline & & & A-PLLA-A (80) & 98.0 & 78.4 & & 121.0 & 206.0 & 1.6 \\
\hline
\end{tabular}

a Determined by ${ }^{1} \mathrm{H}$ NMR

betermined by GPC relative to polystyrene standards with $\mathrm{CHCl}_{3}$ as the eluent.

evident that the latter curve has shifted to a higher molecular weight region without the development of a shoulder peak around the region where the former curve is shown. As summarized in Table 3, the $\mathrm{M}_{\mathrm{n}}$ (gpc) value of each A-PLLA-A $(2 \mathrm{x})$ was approximately twice that of the corresponding A-PLLA(x) in spite of the slightly wider polydispersity shown. These results strongly support the fact that the coupling products were the dimers of A-PLLA(x) and that their $M_{n}($ th $)$ values were equal to $2 x$. Because the $M_{n}(n m r)$ values of A-PLLA-A $(2 \mathrm{x})$ estimated above were almost comparable to the $\mathrm{M}_{\mathrm{n}}(\mathrm{th})$ values, the latter values $(15,21,24,50,70$ and $80 \mathrm{kDa})$ are used as the $2 \mathrm{x}$ for naming the six A-PLLA-A samples.

Synthesis of $\mathbf{t}$-sb-PLAs by the reaction of A-PLLA-A and M-PDLA The Diels-Alder coupling of A-PLLA-A(2x) and M-PDLA(y) was conducted at $140{ }^{\circ} \mathrm{C}$ (Scheme 3 ) to synthesize the t-sb-PLAs. For this purpose, six prepolymers of M-PDLA(y) $(y=3.0,4.5,7.5,10,15$, and 25) were newly prepared (see Supplementary Table $S 1$ in the supporting data) and combined with the A-PLLA-A $(2 \mathrm{x})$ prepolymers $(2 \mathrm{x}=15,21,24,50,70$, and 80$)$ to prepare $\mathrm{t}-\mathrm{sb}-\mathrm{PLA}(\mathrm{y}-2 \mathrm{x}-\mathrm{y})(\mathrm{y}-2 \mathrm{x}-\mathrm{y}$ : 3-24-3, 4.5-21-4.5, 7.5-15-7.5, 10-80-10, 15-70-15, 25-50-25). A typical GPC curve of t-sb-PLA(7.5-15-7.5), as synthesized from A-PLLA-A(15) and M-PDLA(7.5), is presented in Figure 2, in which a significant molecular weight increase is shown with the uni-modal nature preserved. Figure 3 shows the ${ }^{1} \mathrm{H}-\mathrm{NMR}$ spectrum of this product. The expanded region (spectrum $\mathrm{b}_{2}$ ) exhibits new signals at $\delta$ 3.1-3.3 (signal $d$ ) and 3.4-3.6 p.p.m. (signal $c$ ), which can be assigned to the Diels-Alder adducts, together with the faint aromatic and olefinic proton signals from the anthracene $(\delta 7.4-8.5$ p.p.m.) and maleimide moieties ( $\delta 6.75$ p.p.m.), as compared with those shown in Figure 1 (a4) and Figure 3 (b'), respectively. The data supported the quantitative formation of the Diels-Alder adducts between either the terminal groups of A-PLLA-A(15) and M-PDLA(7.5) or the triblock structure of the t-sb-PLAs(7.5-15-7.5).

Table 4 summarizes the synthesis of the six t-sb-PLAs whose PLLA/ PDLA chirality ratios are $1 / 1$ in 7.5-15-7.5 and 25-50-25 but PLLArich in the other products. Their $\mathrm{M}_{\mathrm{n}}(\mathrm{gpc})$ and $\mathrm{M}_{\mathrm{w}}(\mathrm{gpc})$ values were higher than those of the corresponding prepolymers, but the polydispersities were almost comparable with those of the A-PLLA$\mathrm{A}(2 \mathrm{x})$ prepolymers. The $\mathrm{M}_{\mathrm{n}}(\mathrm{gpc})$ values of the lower molecular weight series (7.5-15-7.5, 4.5-21-4.5, and 3-24-3) were also somewhat larger than the $M_{n}(t h)$ values estimated from the total $M_{n}($ th $)$ values of the three prepolymers. In the high molecular weight series
(25-50-25, 15-70-15, and 10-80-10), the $\mathrm{M}_{\mathrm{n}}$ (gpc) values were almost equal to the total $M_{n}($ th $)$ values of the prepolymers. These GPC features are similar to those of the d-sb-PLAs shown above.

\section{Thermal properties of $\mathbf{d}$ - and $\mathrm{t}$-sb-PLAs}

Figures 4 and 5 show the DSC curves of the obtained d- and t-sb-PLA samples in the second heating scan, respectively. Each sample showed both an exothermic peak at approximately $100^{\circ} \mathrm{C}$ and an endothermic peak above $200{ }^{\circ} \mathrm{C}$, which are attributed to the cold crystallization and the subsequent melting of the sc crystals, respectively. No melting behavior of hc crystals was noted, even in the samples having PLLArich compositions. This behavior is similar to that shown by the sbPLA samples prepared by other methods $;{ }^{19}$ however, the samples were different from the polymer blends of PLLA and PDLA homopolymers for which sc crystallization is likely accompanied by homo-chiral crystallization, particularly those of polymers with high $\mathrm{M}_{\mathrm{n}}$. Because the retro Diels-Alder reaction between anthracene and maleimide has been known to take place above $250{ }^{\circ} \mathrm{C},{ }^{20}$ the present adducts are expected to be thermally stable up to the $\mathrm{T}_{\mathrm{m}}$ of the sc crystals.

Figures $6 \mathrm{a}$ and $\mathrm{b}$ show the changes in melting temperature $\left(\mathrm{T}_{\mathrm{ms}}\right)$ and heat of fusion $\left(\Delta \mathrm{H}_{\mathrm{ms}}\right)$, respectively, of the sc crystals, as determined by DSC, plotted as a function of the PDLA content for the various series of $\mathrm{d}$ - and t-sb-PLA samples. For both samples, the $\mathrm{T}_{\mathrm{ms}}$ and $\Delta \mathrm{H}_{\mathrm{ms}}$ become higher as the PLLA/PDLA block ratios approach 1:1 due to the associated increased sc-crystallinity (Tables 2 and 4). Additionally, the effect of the molecular weight distribution is expected to be minimal because the $\mathrm{M}_{\mathrm{w}} / \mathrm{M}_{\mathrm{n}}$ values of the samples were not significantly different from each other. In the d-sb-PLAs, the $T_{m s}$ values were significantly higher in the lower $M_{n}$ series $(30 \mathrm{kDa})$ than in the higher $M_{n}$ series $(100 \mathrm{kDa})$; however, in the t-sb-PLAs, the values became slightly higher in the higher $M_{n}$ series $(100 \mathrm{kDa})$. When the d-sb-PLAs and t-sb-PLAs are compared, the $\mathrm{T}_{\mathrm{ms}}$ values of the former samples were higher than those of the latter samples in the low $\mathrm{M}_{\mathrm{n}}$ series $(30 \mathrm{kDa})$, whereas the opposite relation was exhibited in the high $\mathrm{M}_{\mathrm{n}}$ series $(100 \mathrm{kDa})$. Furthermore, the $\Delta \mathrm{H}_{\mathrm{ms}}$ values were higher in the low $\mathrm{M}_{\mathrm{n}}$ series than in the high $\mathrm{M}_{\mathrm{n}}$ series with PLLA-rich compositions of both the d-sb-PLAs and t-sbPLAs, whereas the values became nearly identical at the equivalent composition of PLLA/PDLA $=1 / 1$. There was also a tendency for the t-sb-PLA samples to show increased crystallinity (or $\Delta \mathrm{H}_{\mathrm{ms}}$ ) versus the d-sb-PLAs with equal PLLA/PDLA compositions within the same $M_{n}$ series. These contrasting results may be explained by the different 


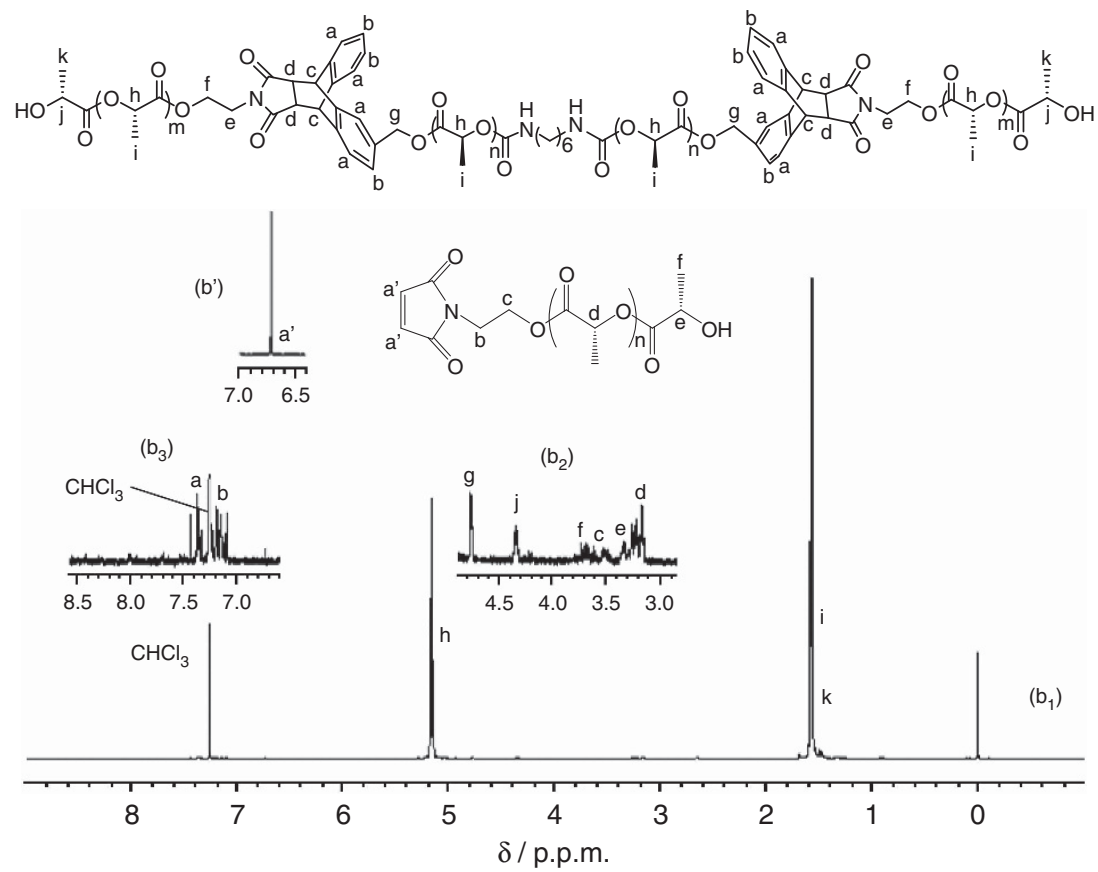

Figure 3 The ${ }^{1} \mathrm{H}$ NMR spectra of the as-prepared t-sb-PLA(7.5-15-7.5): $\left(b_{1}\right)$ the full spectrum, $\left(b_{2}-b_{3}\right)$ the expanded spectra for the weak signals, and $\left(b^{\prime}\right)$ an expanded spectrum of the M-PDLA(7.5) for comparison.

Table 4 The results of Diels-Alder reaction of A-PLLA-A(2x) and M-PDLA(y) to obtain t-sb-PLA(y-2x-y)

\begin{tabular}{|c|c|c|c|c|c|c|c|c|}
\hline$t-s b-P L A y-2 x-y$ & Combination & PDLA (\%) & $\operatorname{Mn}(t h)\left(10^{-3}\right)$ & $M n^{\mathrm{a}}(g p c)\left(10^{-3}\right)$ & $M w^{2}(g p c)\left(10^{-3}\right)$ & $M w / M n^{a}$ & $T_{m}{ }^{\mathrm{b}}(\mathrm{C})$ & $X_{c}^{c}(\%)$ \\
\hline 7.5-15-7.5 & A-PLLA-A (15)/ M-PDLA (7.5) & 50 & 29.4 & 45.3 & 77.0 & 1.7 & 212.0 & 39.9 \\
\hline $4.5-21-4.5$ & A-PLLA-A (21)/ M-PDLA (4.5) & 30 & 29.6 & 43.5 & 82.7 & 1.9 & 204.7 & 31.6 \\
\hline $25-50-25$ & A-PLLA-A (50)/ M-PDLA (25) & 50 & 98.3 & 92.9 & 190.0 & 2.0 & 220.1 & 41.1 \\
\hline $15-70-15$ & A-PLLA-A (70)/ M-PDLA (15) & 30 & 97.9 & 114.0 & 205.0 & 1.8 & 215.0 & 28.2 \\
\hline $10-80-10$ & A-PLLA-A (80)/ M-PDLA (10) & 20 & 98.4 & 109.0 & 207.0 & 1.9 & 211.3 & 18.5 \\
\hline
\end{tabular}

aDetermined by GPC relative to polystyrene standards with $\mathrm{CHCl}_{3}$ as the eluent.

betermined by DSC (the 2nd scan).

${ }^{c}$ Calculated on the basis of the specific heat of fusions of sc crystals $(142 \mathrm{~J} / \mathrm{g})$.

sc-crystallizability of d-sb-PLAs and t-sb-PLAs consisting of different block lengths of PLLA and PDLA. In the lower $M_{n}$ series $(30 \mathrm{kDa})$, the t-sb-PLAs ought to have relatively shorter PDLA blocks than the d-sb-PLAs, which cannot form stable sc-crystallites, exhibiting lower $\mathrm{T}_{\mathrm{ms}}$ values compared to those of d-sb-PLAs. However, the tri-block system is able to attain larger $\Delta \mathrm{H}_{\mathrm{ms}}$ values and higher crystallinities than the di-block system because the tri-block system ideally possesses stronger intermolecular interactions. Similarly, within the high $M_{n}$ series $(100 \mathrm{kDa})$, each of the enantiomeric blocks should have higher exclusion volumes and are likely separated from each other to make their sc crystallization more difficult. This effect was readily observed in the d-sb-PLAs of higher Mn $(100 \mathrm{kDa})$, which show the lowest $\mathrm{T}_{\mathrm{ms}}$ and $\Delta \mathrm{H}_{\mathrm{ms}}$ values. In contrast, $\Delta \mathrm{H}_{\mathrm{ms}}$ or crystallinity became the highest in the t-sb-PLA having an $\mathrm{M}_{\mathrm{n}}$ of $100 \mathrm{kDa}$ and an equivalent composition of PLLA/PDLA $=1 / 1$, for which the block lengths were sufficiently high to effectively form the stable crystals. The $\mathrm{T}_{\mathrm{ms}}$ and $\Delta \mathrm{H}_{\mathrm{ms}}$ may therefore be related to the ease with which the sc crystallites grow and the content of sc crystals formed, respectively. In accounting for crystallinity, the latter is expected to be greater in the t-sb-PLAs, and the $\mathrm{T}_{\mathrm{ms}}$, related to either the crystal size or the lamella thickness, is expected to be larger in the d-sb-PLAs.

It has been reported that sc-crystals with the parallel arrangement of PLLA and PDLA chains are more stable than those with antiparallel arrangements. ${ }^{21}$ The large difference in $\mathrm{T}_{\mathrm{ms}}$ between the $\mathrm{t}$-sbPLA and d-sb-PLAs may be related to the different arrangements of the enantiomeric blocks, although the present data are not sufficient to draw a conclusion. However, the glass transition temperature $\left(\mathrm{T}_{\mathrm{g}}\right)$ values are nearly equivalent for the d-sb-PLA and t-sb-PLA samples with similar amorphous domains.

\section{Thermomechanical properties of polymer films of $\mathbf{d}$ - and}

\section{t-sb-PLAs}

The above d- and t-sb-PLA samples of high $\mathrm{M}_{\mathrm{n}}$ series were fabricated into polymer films by ordinary hot-pressing at $240{ }^{\circ} \mathrm{C}$ and subsequent annealing at $140^{\circ} \mathrm{C}$ for crystallization. The resulting polymer films were nearly transparent following annealing. Figure 7 shows the typical WAXS patterns of the representative films of the d- and t-sbPLAs with PLLA/PDLA $=50 / 50$ before and after annealing. It is 
evident that the melt-quenched films were amorphous, whereas the annealed films became highly crystalline, forming only sc crystals. The DSC analysis of these films (see Supplementary Table S2 in the Supplementary data) also supported the complete sc crystallinity of the annealed d- and t-sb-PLA films, except for the film of t-sb-PLA

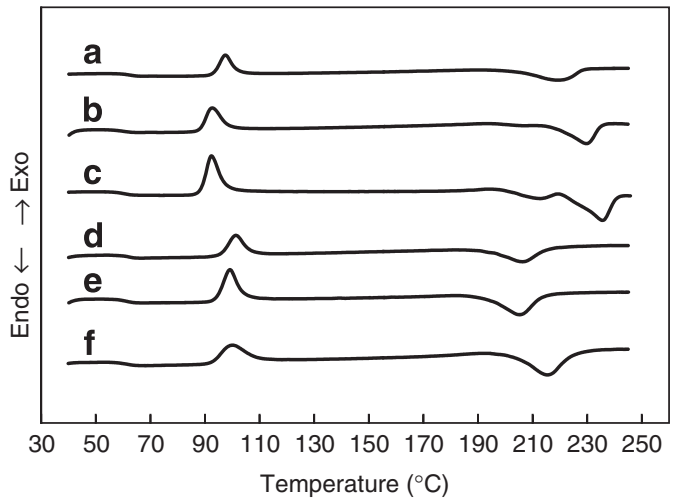

Figure 4 The DSC curves of d-sb-PLAs(x-y), $x-y$ : (a) 24-6, (b) 21-9, (c) 15-15, (d) 80-20, (e) 70-30, and (f) 50-50 (in the second heating scan).

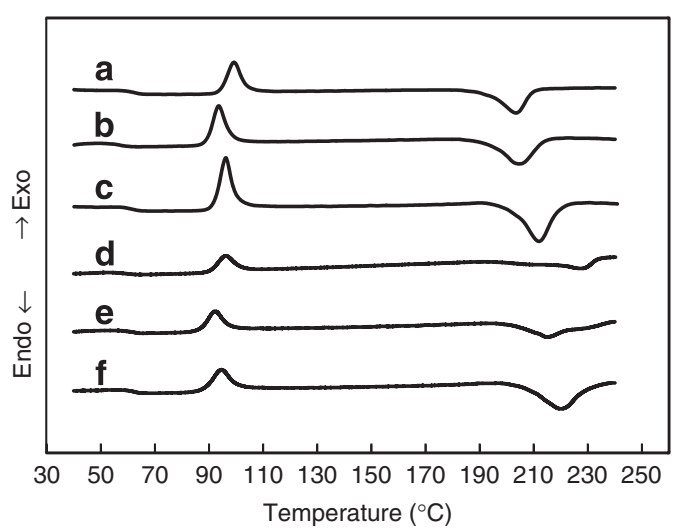

Figure 5 The DSC curves of t-sb-PLA(y-2x-y), y-2x-y: (a) 3-24-3, (b) $4.5-$ 21-4.5, (c) 7.5-15-7.5, (d) 10-80-10, (e) 15-70-15, and (f) 25-50-25 (in the second heating scan).

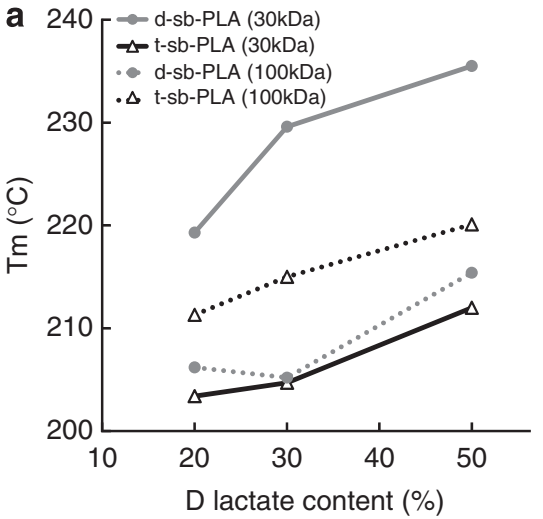

(15-70-15), which exhibited a small amount of he crystals $(4.5 \%)$ in conjunction with sc crystals. The small amount of he crystals may have been produced during the long annealing process carried out at $140^{\circ} \mathrm{C}$. In contrast, the d-sb-PLA (70-30) with a PLLA/PDLA composition identical to that of the t-sb-PLA (15-70-15) showed a lack of hc crystallization following annealing. Therefore, we believe the two PDLA side blocks of t-sb-PLA (15-70-15) are too short to completely suppress the he crystallization of the long PLLA center block. The sc crystallinities of the t-sb-PLA (25-50-25) and d-sb-PLA (50-50) were determined to be 49.3 and $36.6 \%$, respectively, whereas those of the t-sb-PLA (15-70-15) and d-sb-PLA (70-30) were 33.2 and $30.2 \%$, respectively. The t-sb-PLA system appears to exhibit a slightly higher crystallinity than the d-sb-PLA system, likely because of the stronger intermolecular interactions of the former. Because the annealed films retained transparency, the sc crystals involved are likely small in size. Figure 8 shows the rheological properties of the $\mathrm{d}$ - and t-sb-PLA films compared with those of a PLLA film $\left(\mathrm{M}_{\mathrm{n}}=100\right.$ $\mathrm{kDa}$, control). It can be observed that the drop in $\mathrm{G}^{\prime}$ was suppressed up to $200{ }^{\circ} \mathrm{C}$ in both the $\mathrm{d}$ - and t-sb-PLA films. In particular, the t-sbPLA(25-50-25) film, showing the highest $\mathrm{T}_{\mathrm{ms}}$ and $\Delta \mathrm{H}_{\mathrm{m}}$, exhibited the highest thermal resistivity in terms of the modulus drop throughout the whole temperature range (Figure 8a). Even around the $\alpha$

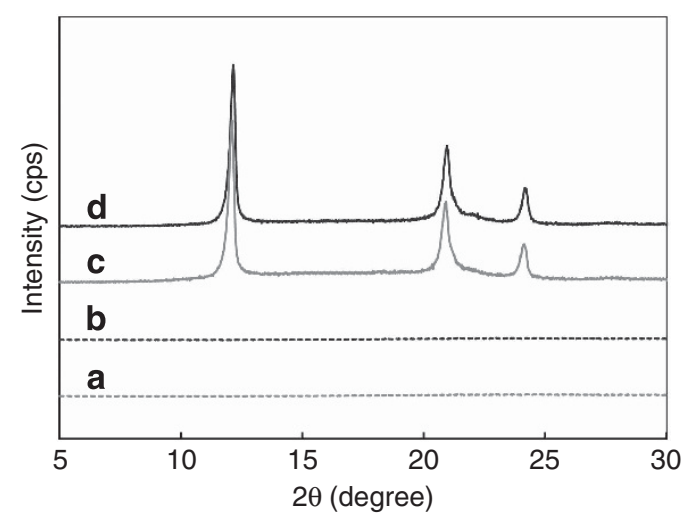

Figure 7 The WAXS patterns of the (a) melt-quenched and (c) annealed films of d-sb-PLA: 50-50 and the (b) melt-quenched and (d) annealed films of t-sb-PLA: 25-50-25. Due to the normalization of the intensities, the diffraction curves of (a) and (b) were flattened.

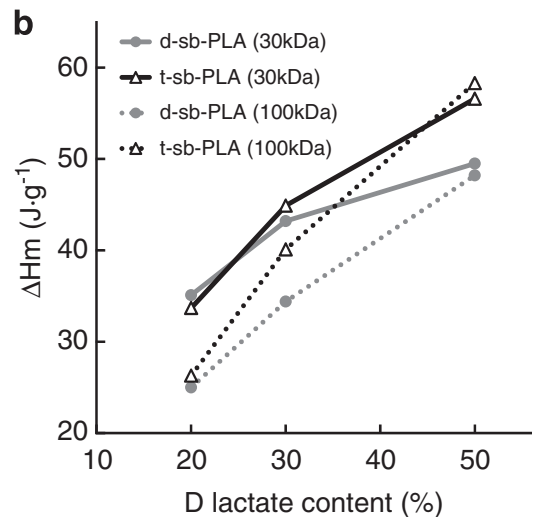

Figure 6 The changes in $\mathrm{T}_{\mathrm{ms}}$ (a) and $\Delta \mathrm{H}_{\mathrm{ms}}$ (b) plotted as a function of PDLA content for the $\mathrm{d}$ - and $\mathrm{t}$-sb-PLA samples of the two series of $\mathrm{M}_{\mathrm{n}}=30$ and $100 \mathrm{kDa}$. 


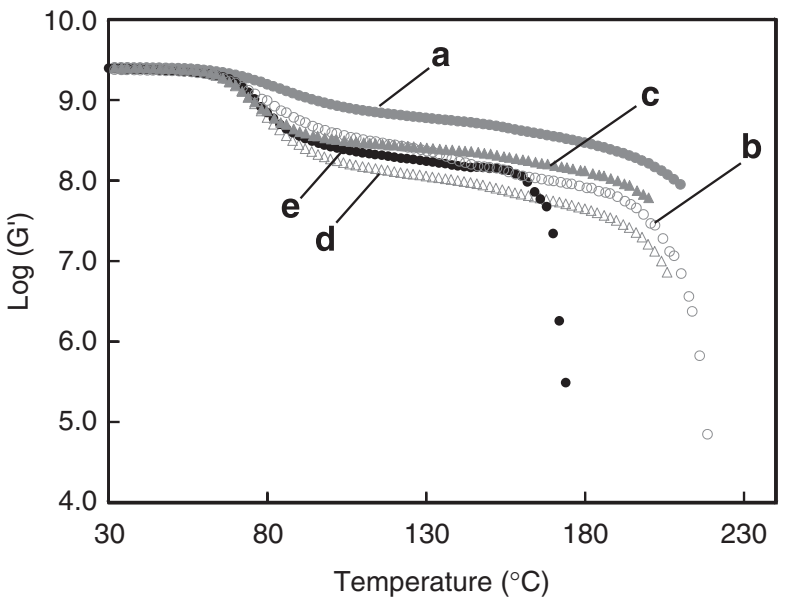

Figure 8 The thermomechanical properties of the melt-quenched and annealed films of t-sb-PLA(y-2x-y), $y-2 x-y=$ (a) 25-50-25 and (b) 15-7015 , and d-sb-PLA(x-y), $x-y=$ (c) 50-50 and (d) 70-30, as compared with those of (e) a PLLA film (control).

relaxation temperature ( or $T_{g}$ ), the change in $G^{\prime}$ was minimized. The $\mathrm{t}$-sb-PLA films showed lower G' changes than the d-sb-PLA films with identical compositions. This behavior also can be attributed to the favored intermolecular interactions within the tri-block system. Therefore, $\mathrm{t}$-sb-PLAs can provide thermo-resistant plastic materials for a variety of applications.

\section{CONCLUSIONS}

The $\mathrm{d}$ - and t-sb-PLA copolymers with different PLLA and PDLA block lengths and compositions were successfully prepared by utilizing the terminal Diels-Alder coupling method. The prepolymers of A-PLLA and M-PDLA were first prepared by the ROP of L- and D-lactides, respectively, and the di-anthracene-terminated A-PLLA-A was successfully synthesized by the reaction of A-PLLA and HMDI. Then, combinations of A-PLLA/M-PDLA and A-PLLA-A/M-PDLA gave d-sb-PLAs and t-sb-PLAs by spontaneous Diels-Alder coupling. Their block lengths and sequences were determined by the molecular weights of the prepolymers, as first synthesized. The resultant d-sb$\operatorname{PLA}(x-y)$ and $t-s b-P L A(y-2 x-y)$ were found to have different thermal properties. The d-sb-PLA(15-15), which consisted of an equivalent length of the two enantiomeric blocks, showed the highest $\mathrm{T}_{\mathrm{ms}}$ in the copolymers. The t-sb-PLAs were readily fabricated into transparent polymer films by hot-pressing. These films were found to have excellent thermal stability and mechanical properties because of the high sc crystallinity. This synthetic method, based on terminal couplings, can afford a convenient route to the fabrication of stereo block copolymers of PLLA and PDLA showing different thermal and mechanical properties.

\section{ACKNOWLEDGEMENTS}

This work was part of a commissioned project, 'Development of the Fundamental Technology on Green and Sustainable Chemical Processes' that was supported by New Energy and Industrial Technology Development Organization (NEDO). Musashino Chemical Laboratory, Ltd. and Unitica Co., Ltd. are highly acknowledged for their support and helpful discussions.

1 Kimura, Y. Molecular, structural, and material design of bio-based polymers design of bio-based polymers. Polymer. J. 41, 797-807 (2009).

2 Lunt, J. Large-scale production, properties and commercial applications of polylactic acid polymers. Polym. Degrad. Stab. 59, 145-152 (1998).

3 Ajioka, M., Enomoto, K., Suzuki, K. \& Yamaguchi, A. The basic properties of poly(lactic acid) produced by the direct condensation polymerization of lactic acid. J. Environ. Polym. Degrad. 3, 225-234 (1995).

4 Moon, S. -I., Lee, C. -W., Taniguchi, I., Miyamoto, M. \& Kimura, Y. Melt/solid polycondensation of L-lactic acid: an alternative route to poly(L-lactic acid) with high molecular weight. Polymer 42, 5059 (2001).

5 Dorgan, J. R., Lehermeier, H. \& Mang, M. Thermal and Rheological Properties of commercial-grade poly(lactic acid)s. J. polym. Environ. 8, 1-9 (2000).

6 Ikada, Y., Jamshidi, K., Tsuji, H. \& Hyon, S. H. Stereocomplex formation between enantiomeric poly(lactides). Macromolecules 20, 904-906 (1987).

7 Tsuji, H., Hyon, S. H. \& Ikada, Y. Stereocomplex formation between enantiomeric poly(lactic acid)s. 3. Calorimetric studies on blend films cast from dilute solution. Macromolecules 24, 5651-5656 (1991).

8 Tsuji, H., Hyon, S. H. \& Ikada, Y. Stereocomplex formation between enantiomeric poly(lactic acids). 5. Calorimetric and morphological studies on the stereocomplex formed in acetonitrile solution. Macromolecules 25, 2940-2946 (1992).

9 Tsuji, H. \& Ikada, Y. Stereocomplex formation between enantiomeric poly(lactic acid)s. 6. Binary blends from copolymers. Macromolecules 25, 5719-5723 (1992).

10 Tsuji, H. \& Ikada, Y. Stereocomplex formation between enantiomeric poly(lactic acids). 9. Stereocomplexation from the melt. Stereocomplex formation between enantiomeric poly(lactic acids). 9. Stereocomplexation from the melt. Macromolecules 26, 6918-6926 (1993).

11 Fukushima, K., Furuhashi, Y., Sogo, K., Miura, S. \& Kimura, Y. Stereoblock poly(lactic acid): synthesis via solid-state polycondensation of a stereocomplexed mixture of Poly(L-lactic acid) and poly(D-lactic acid). Macromol. Biosci. 5, 21-29 (2005).

12 Fukushima, K. \& Kimura, Y. A Novel synthetic approach to stereo-block poly(lactic acid). Macromol. Symp. 224, 133-144 (2005).

13 Fukushima, K. \& Kimura, Y. Stereocomplexed polylactides (Neo-PLA) as highperformance bio-based polymers: their formation, properties, and application. Polym. Int. 55, 626-642 (2006).

14 Fukushima, K. \& Kimura, Y. An Efficient solid-state polycondensation method for synthesizing stereocomplexed poly(lactic acid)s with high molecular weight. J. Polym. Sci., Part A: Polym. Chem. 46, 3714-3722 (2008).

15 Hirata, M. \& Kimura, Y. Thermomechanical properties of stereoblock poly(lactic acid)s with different PLLA/PDLA block compositions. Polymer 49, 2656 (2008).

16 Kakuta, M., Hirata, M. \& Kimura, Y. Stereoblock polylactides as high-performance biobased polymers. J. Macromol. Sci., Part C: Polym. Rev. 49, 107-140 (2009).

17 Hirata, M., Kobayashi, K. \& Kimura, Y. Synthesis and properties of high-molecularweight stereo di-block polylactides with nonequivalent D/L ratios. J. Polym. Sci., Part A: Polym. Chem. 48, 794-801 (2010).

18 Hirata, M., Kobayashi, K. \& Kimura, Y. Enhanced stereocomplexation by enantiomer adjustment for stereo diblock polylactides with non-equivalent D/L Ratios. Macromol. Chem. Phys. 211, 1426-1431 (2010).

19 Masutani, K., Kawabata, S., Aoki, T. \& Kimura, Y. Efficient formation of stereocomplexes of poly(L-lactide) and poly(D-lactide) by terminal Diels-Alder coupling. Polym. Int. 59, 1526-1530 (2010).

20 Jones, J. F., Liotta, C. L., Collard, D. M. \& Schiraldi, D. A. Cross-linking and modification of poly(ethylene terephthalate-co-2,6-anthracenedicarboxylate) by diels alder reactions with maleimides. Macromlecles 32, 5786-5792 (1999).

21 Brizzolara, D., Cantow, H. J., Diederichs, K., Keller, E. \& Domb, A. J. Mechanism of the stereocomplex formation between enantiomeric poly(lactide)s. Macromolecules 29 191-197 (1996).

Supplementary Information accompanies the paper on Polymer Journal website (http://www.nature.com/pj) 